World Maritime University

The Maritime Commons: Digital Repository of the World Maritime University

2020

\title{
Oil spill response training in the south baltic sea region
}

Dimitrios Dalaklis

Anastasia Christodoulou

Momoko Kitada

Follow this and additional works at: https://commons.wmu.se/lib_presentations

This Presentation Open Access is brought to you courtesy of Maritime Commons. Open Access items may be downloaded for non-commercial, fair use academic purposes. No items may be hosted on another server or web site without express written permission from the World Maritime University. For more information, please contact library@wmu.se. 
OIL SPILL RESPONSE TRAINING IN THE SOUTH BALTIC SEA REGION

Dimitrios Dalaklis, Anastasia Christodoulou and Momoko Kitada

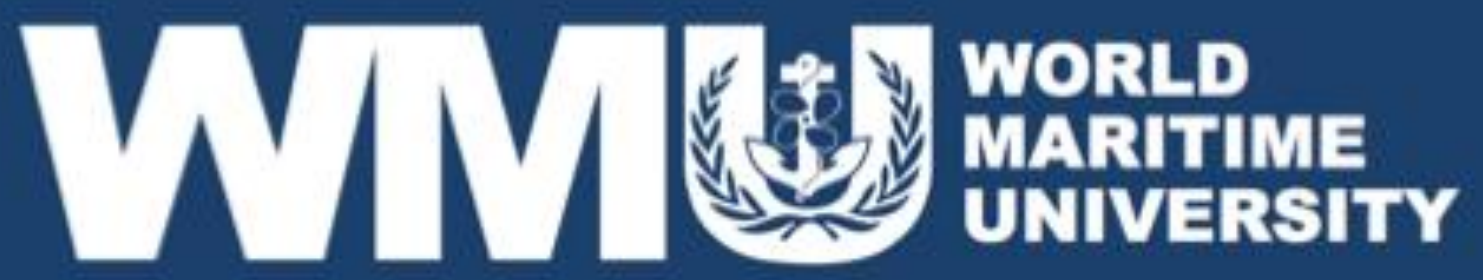




\section{Outline}

- Introduction to the topic of oil spill response and especially the difficulties of "field activities";

- Discussing the scenario setting;

- Most important findings of the TTX;

- Summary and Conclusion... 


\section{Introduction}

The contemporary world still relies heavily on oil to cover its energy needs.

- Unfortunately, oil spills close to the locations of production and processing infrastructure, or during transport continue to be one of the major threats both to society and environment at the global level.

- The United Nations' Sustainable Development Goal 14, requires protection of our ocean, marine life and resources; therefore, "minimizing" possible oil spill incidents and their adverse impacts should be deemed as a very high priority... 


\section{Introduction}

- For successful resolution of oil spill incidents, close and effective international cooperation -especially between neighbouring countries that usually "share the burden" of oil pollution- is a vital necessity.

- On this basis, the South Baltic Oil (SBOIL) project aims to strengthen the existing oil spill response capacities in the South Baltic region, introducing a cross-border spill response tool based on the new "green technology" of biodegradable oil binders (BioBinders). 


\section{Discussing the Scenario Setting:}

- The objectives of the exercise were to test the compatibility of regional and national plans; to identify the various countries' actions in response to an oil spill incident; to evaluate/prove cross border Command \& Control (based on the information from the regional and national plans); and to investigate via a realistic scenario the challenges of using BioBind as a response option.
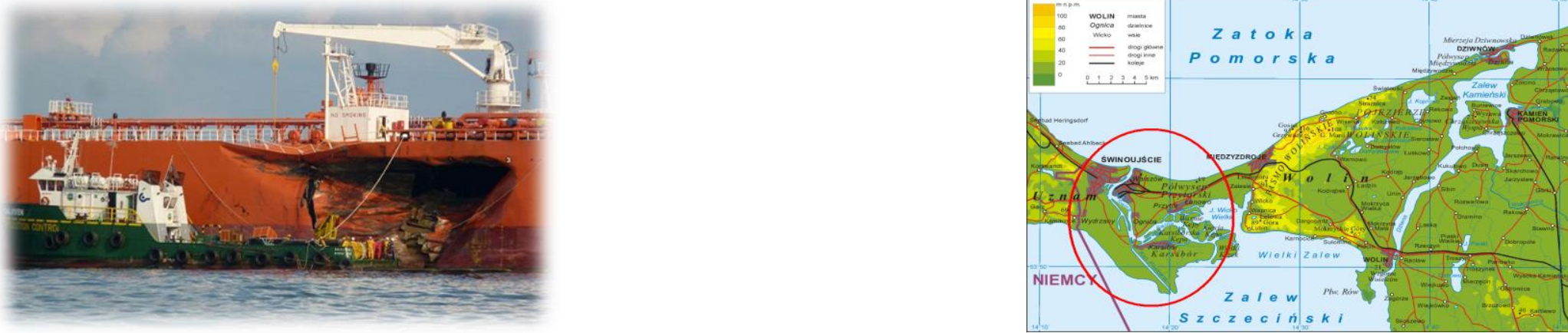


\section{Discussing the Scenario Setting:}

- The overall aim of the exercise was to test the participating countries collaboration to mobilise and respond to an offshore oil spill incident within the Exclusive Economic Zone (EEZ) of one country that then migrates across to another EEZ of an adjoining country.

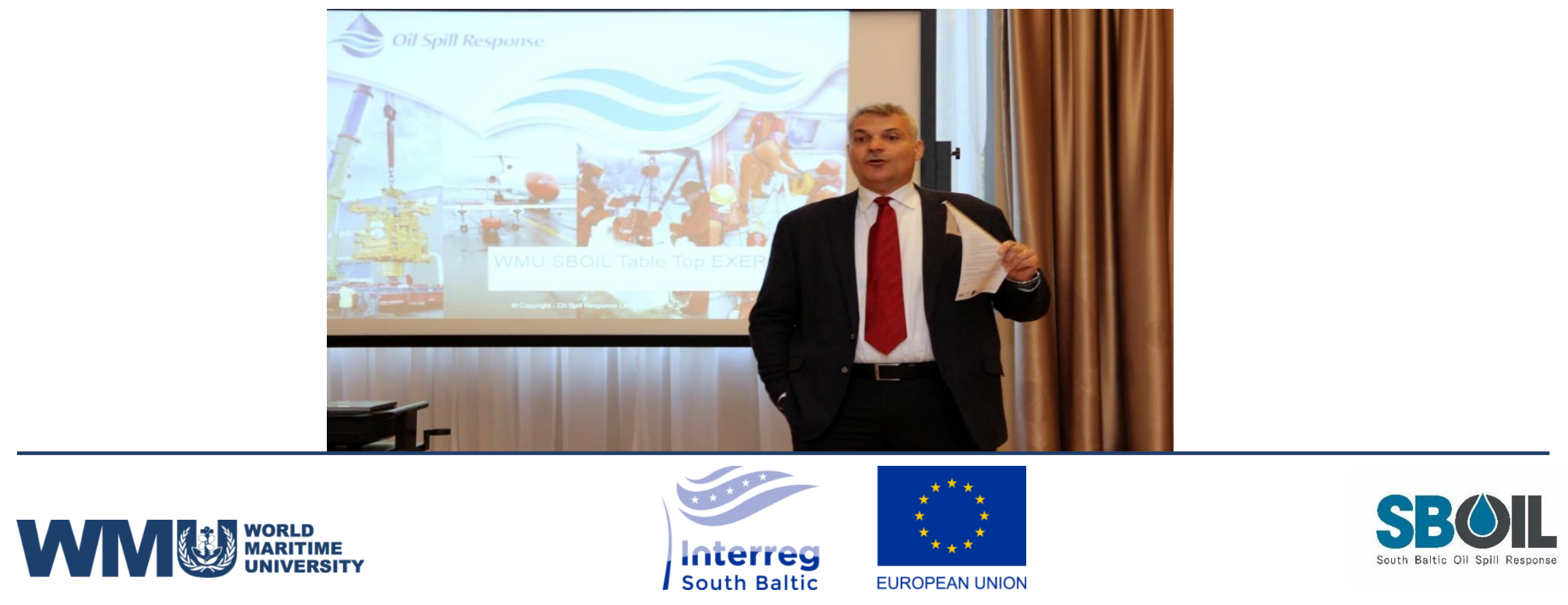




\section{Discussing the Scenario Setting:}

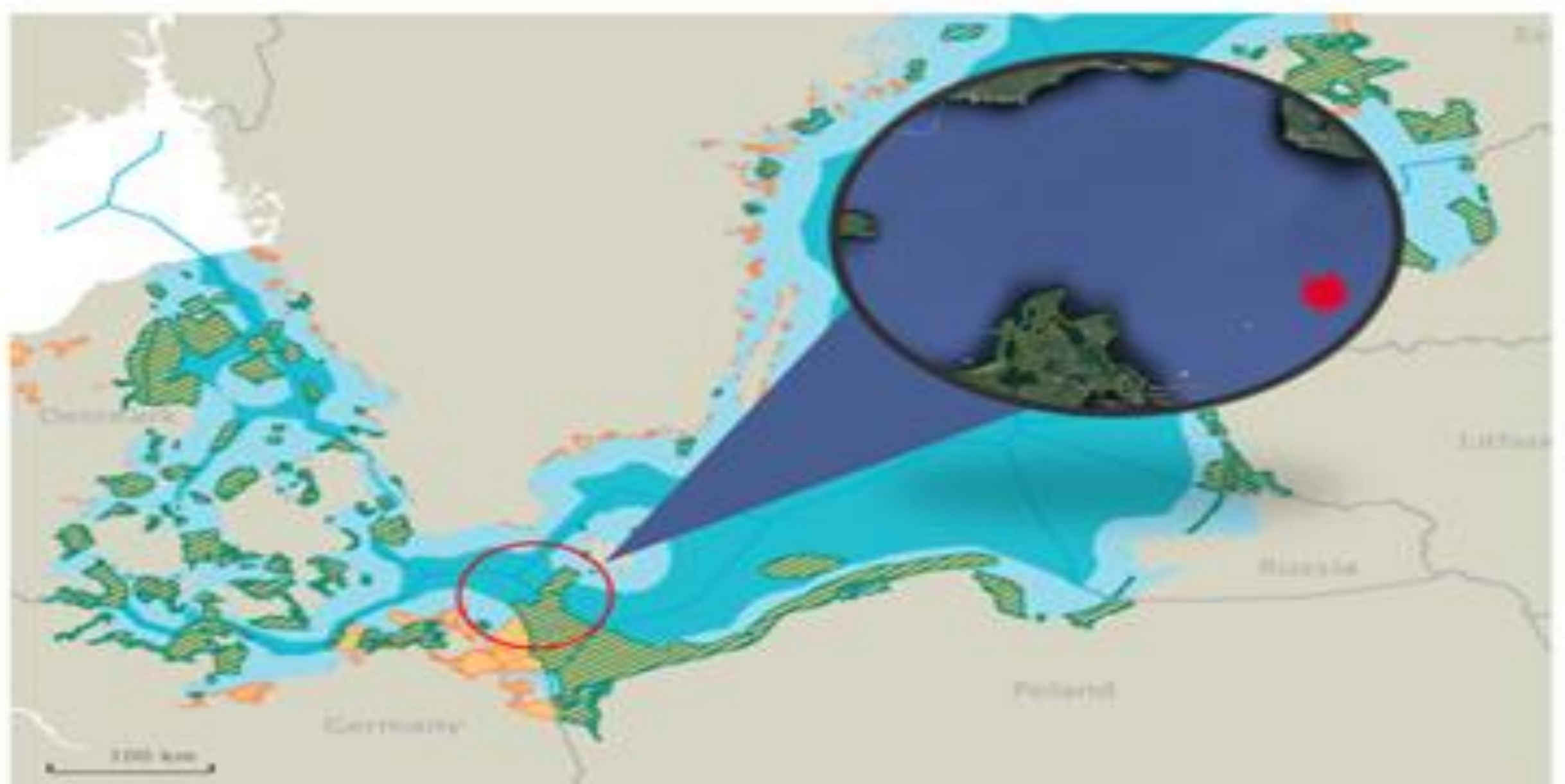

Two vessels colliding within Polish waters (a container vessel and a tanker), close to the EEZ of Germany. Significant loss of crude oil into the water was reported. 


\section{Conduct of the TTX:}

Two groups were established, allowing participants to 'mix' and use their experience to work through the scenario and propose course of action based on their knowledge of each country's legislation and procedures. (Polish vs German/Swedish contingent)

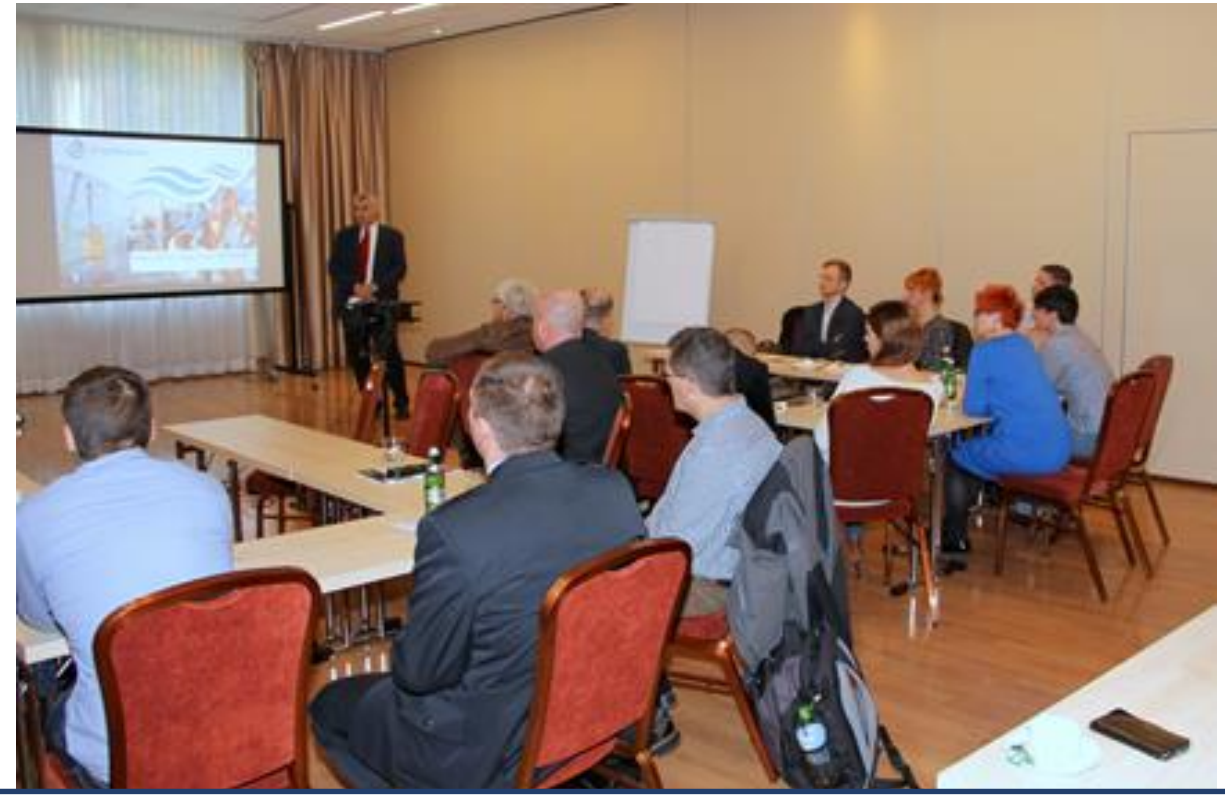




\section{Conduct of the TTX:}

An initial response assessment of the incident was worked through, as this is an important part of understanding the scale and complexity of the incident.

- Suggestions for gathering further information on the magnitude of the incident, the hazard and safety concerns and initial priorities (including aerial surveillance and satellite surveillance, together with the information that could be obtained by personnel at the incident site) were discussed by/amongst the two groups. 


\section{Conduct of the TTX:}

When the response strategies and tactics were covered, the assumption that the groups would only consider the tactical operations that they are familiar with was proved correct.

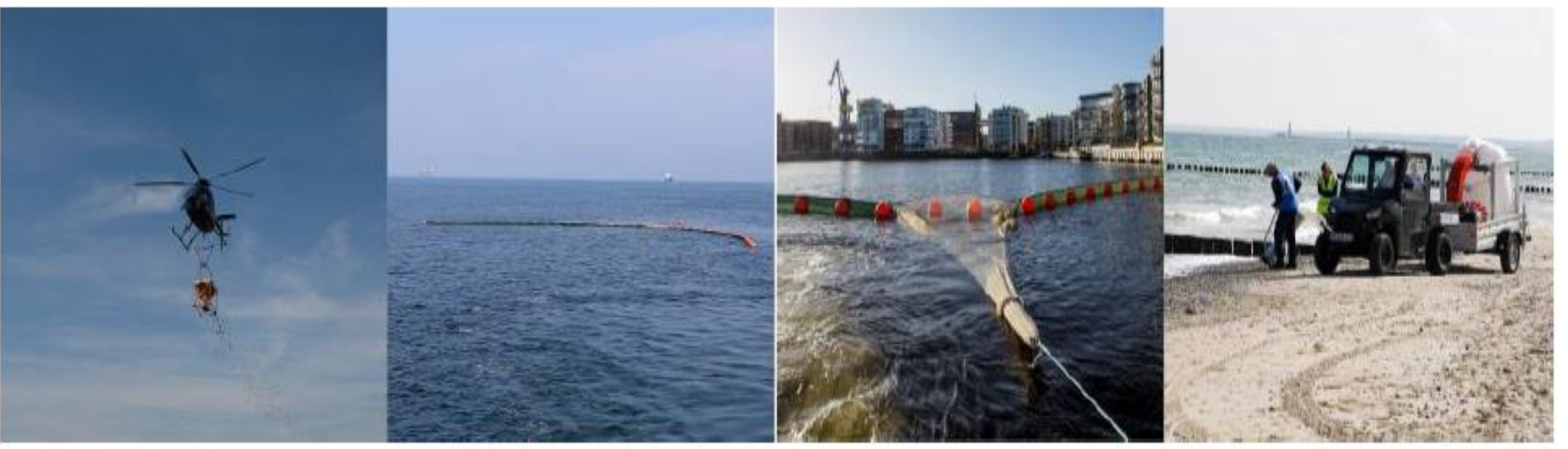




\section{Conduct of the TTX:}

Aerial delivery of BioBinders was ruled out and Offshore Containment and Recovery were the preferred offshore response options for this incident.

Facilitators asked the groups to consider BioBinders as the primary offshore and shoreline response to this scenario and to plan the mobilisation and operations for their use.

- BioBinders can be used in conjunction with other response options; using simultaneous operations (SIMOPS) was "proposed" as a method to manage multiple tactics in response to the same incident! 


\section{"Pre-planned" Response?}

Notification - in the event of an incident happening (crisis situation?) knowing in advance who to contact and how, is essential to ensure that sufficient resources can be available and directed in good time towards the location of the incident.

Understanding the incident (rule of Ws) will help determine its complexity...

Multiple sources to obtain relevant information can result into "information overload"; prioritizing via a limited number of justifiable assumptions can create the "best" response option available to use! 


\section{Conduct of the TTX:}

To streamline an efficient and effective response there are many things that can be prearranged and therefore not hinder the tempo/speed of response.

These include knowing how equipment is to be deployed, the timescales from mobilisation to operation, who has authority to make the decisions and whether everything complies with local and regional legislation - the later issue becomes even more apparent during a multi-country cross border incident.... 


\section{Conduct of the TTX:}

\section{INCIDENT PREPAREDNESS}

- How is the Biobind lo be depployed onto the spill:

- Aerial defloyment

- What type da acrat?

- Vessel deployment

" What sizelype d vesed

- Shougeting deployment

- Where are the stockpiles of Biobind held:

- Who is the contad to mobilise the ouquipment

- What additonal resources are requifed to prepare the artcrathessel to deploy the BloBind

- Who has authority to mobilise these resources

\section{INCIDENT PREPAREDNESS}

- What section/person would have responsibility for the mobilsation?

- Is a contract in place for transport?

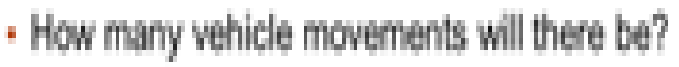

- How would the Biobind be loaded for transpout?

- Are there any transportation resirictions? (weekend driving etc.)

- What restources are needed for unlaading?

- Who is responsibible for chartering vessels or aircrifit?

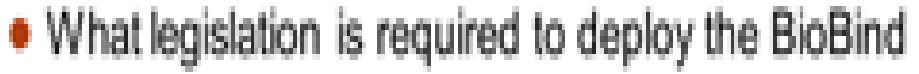

- What can be prepared polot to the incident

- What can only be agreed during the incedent

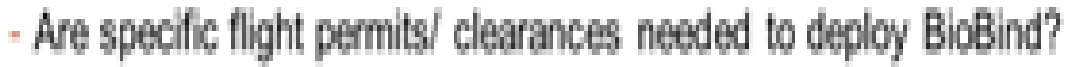

- Can any pild dotoy Biobind? 


\section{Summary and Conclusion}

- Maritime transport activities are quite often associated with oil spills, which in turn impact very negatively the marine environment.

- Although the number of oil spills globally has a decreasing trend, their impact still remains a major concern, especially for those cities and communities near the coastline.

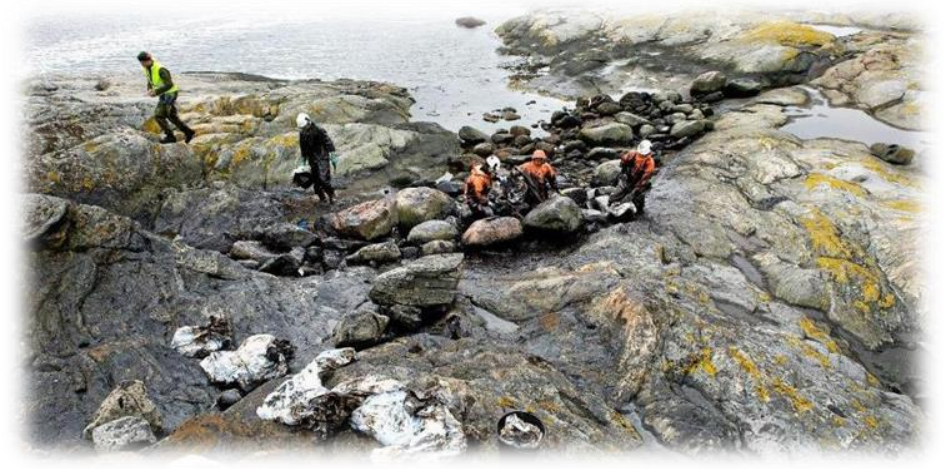




\section{Oil Spill Contingency Planning in the South Baltic Sea Region:}
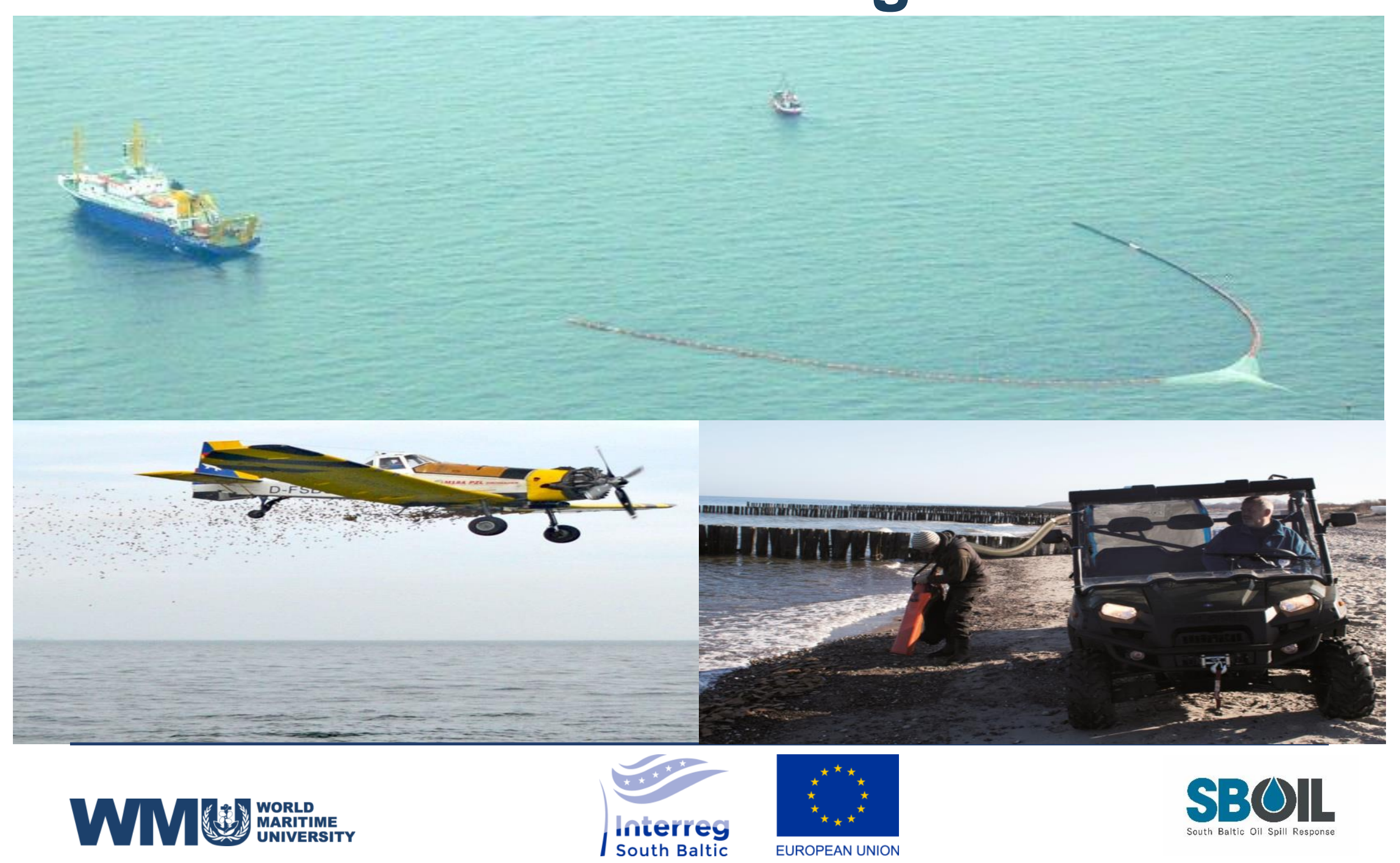

SBOIL 


\section{Summary \& Conclusion}

The specific TTX included the discussion of different scenarios (options) about mobilisation for an offshore response...

- Examined the topics of recovery and waste management, including alternative techniques available for oil spill response.

- Special emphasis to identify the PROS vs CONS when using the BioBind material.

- Focused on highlighting the training needs in cross-border collaboration and increase awareness regarding oil spills and their consequences. 


\section{Summary \& Conclusion}

The overall impression of the participants was that the specific exercise served well the intended purpose and that the use of BioBinders is a rather promising concept.

- On the other hand, there was a consensus that the use of these biodegradable wood-based oil binders on the field is for the time being associated with challenges difficult to overcome, with the quantity and time needed to deploy the required amount of binders to successfully absorb a large volume of oil standing out. 
OIL SPILL RESPONSE TRAINING IN THE SOUTH BALTIC SEA REGION

Dimitrios Dalaklis, Anastasia Christodoulou and Momoko Kitada

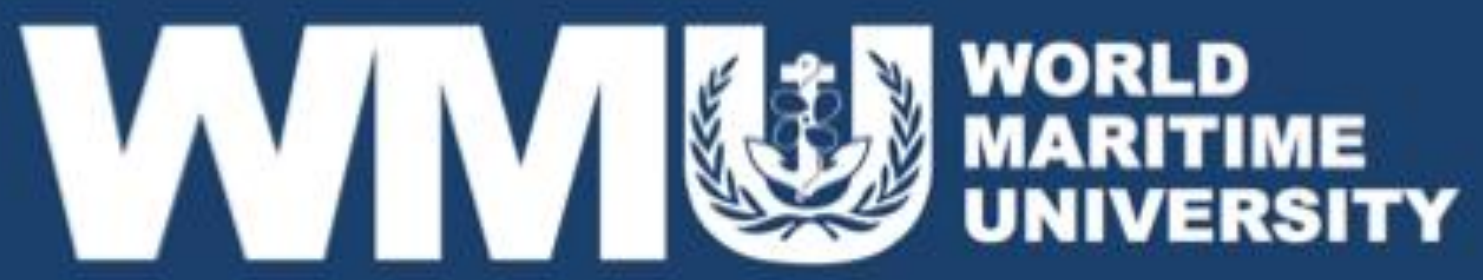

